Relations industrielles

Industrial Relations

\title{
Values and Interests in Social Change, Sister Marie Augusta Neal, S.N.D., Prentice-Hall, Englewood Cliffs, N.J. 1965, 182 pages.
}

\section{Fernand Blais}

Volume 20, numéro 3, 1965

URI : https://id.erudit.org/iderudit/027605ar

DOI : https://doi.org/10.7202/027605ar

Aller au sommaire du numéro

Éditeur(s)

Département des relations industrielles de l'Université Laval

ISSN

0034-379X (imprimé)

1703-8138 (numérique)

Découvrir la revue

Citer ce compte rendu

Blais, F. (1965). Compte rendu de [Values and Interests in Social Change, Sister Marie Augusta Neal, S.N.D., Prentice-Hall, Englewood Cliffs, N.J. 1965, 182 pages.] Relations industrielles / Industrial Relations, 20(3), 581-581.

https://doi.org/10.7202/027605ar

Tous droits réservés @ C Département des relations industrielles de l'Universite Laval, 1965
Ce document est protégé par la loi sur le droit d'auteur. L’utilisation des services d’Érudit (y compris la reproduction) est assujettie à sa politique d'utilisation que vous pouvez consulter en ligne.

https://apropos.erudit.org/fr/usagers/politique-dutilisation/ 
cipes connus tout en plaçont son anolyse dans le cadre du marginalisme. Conçu pour l'enseignement, il peut être très utile sans être le volume idéal, qui, en fait, n'existe pas encore!

\section{Fernand Blois}

The Arts in Society, Edited by Robert $N$. Wilson, Prentice-Hall Inc. Englewood Cliffs, New Jersey, 1964, 372 poges.

Relations entre sciences sociales et orts.

- Pour comprendre un travail d'art dans son sens le plus complet il fout connaitre de foçon intime le travail lui-même, la personnalité de son créoteur et le milieu social qui forment le cadre environnont pour l'artiste, l'art et le public.

Cette remorque de l'éditeur Robert Wilson, dans sa préfoce, caractérise bien l'objet dé ce symposium: définir davantage les interrelations entre l'art, lo société et la personnolité de l'ortiste.

L'auteur n'a pas voulu construire un schème théorique, mais bien de montrer que l'ort ne se fonde pas sur les seules critiques internes, l'explication psychologique ou l'ossociotion sociologique. L'art est trop complexe pour qu'on puisse l'expliquer par un seul facteur.

Deux genres d'études sont présentés par l'éditeur. Le premier groupe tente de décrire la carrière des artistes dans la société moderne. Ainsi nous retrouvons dans les différents chapitres: "Le poète dans la société américaine », Le compositeur aliéné », * Le recrutement des ortistes . Le second groupe d'études discute certains travaux, la personnalité d'artistes et aussi certaines formes d'ort: « L'accueil fait à Dostoevski en Allemagne: 1880-1920 », Robinson Crusoé, un mythe $*$ Les changements institutionnels dans le monde de la peinture française », \&ittérature et société 》...

Enfin, on peut dire que ceux qui étudient le comportement humain peuvent acquérir beoucoup par les arts parce que ceux-ci sont des a représentations symboliques a de - quelque chose * dans la société qui leur a donné naissance ». (p. VI)

Parmi les outeurs de ces essais, il faut noter certains professeurs de réputation internotionale: Edward Shils, Hanz Speier, Ion Wat et Leo Lowenthal.

Fernand Blais
Volues and Interests in Social Change, Sister Marie Augusto Neol, S.N.D., Prentice-Hall, Englewood Cliffs, N.J., 1965. 182 pages.

Les gens cherchent une explications oux chongements sociaux. Les théories de Darwin et Degel semblent trop abstraites ou trop inclusives pour decrire adéquatement la résistance ou l'acceptation des pressions quo. tidiennes pour le changement.

D'un autre côté, puisque ces pressions sont à la fois partie de notre expérience quotidienne et portie d'un processus historique, on peut examiner la relation qui existe entre la direction des tendances historiques et le dialogue de la prise de décisions.

Au cours de dix chapitres, en plus de plusieurs tableaux, l'auteur développe une méthode pour analyser styles of response, conceptions of the world, ways of interocting, standards accepted, and decisions made, characterising social process at the face-toface and mass communication levels of daily living $»$. (p. iii)

Le volume est basé sur un échantillon composé de prêtres cotholiques répondant au stimulus du changement dans les relations d'une communauté locale. *These priests are currently decision-mokers facing change in an historical significant moment

En plus, l'étude fut faite ovant le Second Concile du Votican, ce qui coractérise davantage ce travail, puisque plusieurs des prêtres interrogés furent nommés comme consultants au Vatican 11.

L'auteur o ainsi foumi un profil objectif de l'échantillon et a aussi présenté un modèle pour la mesure des otitudes vis-ż-vis les valeurs, intérêts, changements et nonchangements applicables avec certaines modifications mineures selon le groupe politique, économique ou social aussi bien que pour les orgonisotions religieuses. Disons enfin que ce livre peut-être un instrument pour tous les professionnels dans les champs de la sociologie, du travail social, l'enseignement et l'administration des affaires.

\section{Fernand Blais}

Public Assistance, Too Much or Too Little?, Duncon M. Maclntyre, Série: The Dimensions of Poverty and Its Remedies, New York State School of Industrial and Labor Relations, Cornell University, Ithaca, New York, Bulletin 53-1, December 1964 86 pages. 